\title{
Evaluation of early patient satisfaction with visual analogue scale in the treatment of isolated great saphenous vein insufficiency with n-Butyl cyanoacrylate ablation
}

\author{
İzole büyük safen ven yetmezliğinin $\mathrm{n}$-Butyl siyanoakrilat ile ablasyon \\ tedavisinde erken dönem hasta memnuniyetinin vizüel analog skala ile \\ değerlendirilmesi
}

\author{
Mehmet Şenel BADEMci ${ }^{\circ}$, Cemal KOCAASLAN ${ }^{\circ}$, Mustafa ALDAĞ ${ }^{\circ}$, Ahmet ÖZTEKIN $\mathbb{C}^{\circ}$, \\ Emine Şeyma DENLI YALVAÇ ${ }^{\mathbb{D}}$, Ebuzer AYDIN $\mathbb{C}$
}

ABSTRACT

Aim: In this study, we aimed to evaluate the early results of n-butyl cyanoacrylate ablation (n-BSA) treatment and patient satisfaction using visual analogue scale (VAS) in the treatment of isolated great saphenous vein (GSV) insufficiency.

Method: Seventy-two patients with GSV diameter between 6-9 $\mathrm{mm}$ and a reflux time of $>0.5$ seconds in clinical grades of C1-C4 according to the Comprehensive Classification System for Chronic Venous Disorders (CEAP) who were treated with n-BSA percutaneous endovenous embolization between January 2016 and July 2017 due to GSV insufficiency were enrolled in the study. Preoperative and postoperative 1. and 6. month evaluations were made using VAS and venous color duplex ultrasonography (CDUS). All data were retrieved retrospectively from patient files, and then evaluated.

Results: Preoperative, and postoperative 1. and 6. month-VAS scores were 6.05, 1.8 and 1.66 respectively. The difference between postoperative 1. and 6. month-VAS scores was not significant ( $p>0.05)$, but the differences between preoperative and postoperative 1. and 6 . month scores were statistically significant $(p<0.001)$. Venous CDUS performed at postoperative 1. and 6. months showed GSV closure rates of $97 \%$ and $95 \%$ respectively. Evaluation of early period outcomes of $n$-BSA embolization treatment performed for isolated GSV incompetence with regard to patient satisfaction using VAS, showed significant positive relationship in preoperative and early period postoperative period.

Conclusion: VAS can be used as an effective method to evaluate early period patient satisfaction related to n-BSA method used for the treatment of isolated great saphenous vein treatment.

Keywords: Venous insufficiency, cyanoacrylate, visual analog scale
Öz

Amaç: Bu çalışmada, izole büyük safen ven (BSV) yetmezliğinin tedavisinde $n$-butil siyanoakrilat ablasyon (n-BSA) tedavi yönteminin erken dönemde etkinliğinin ve vizüel analog skala (VAS) kullanılarak hasta memnuniyetinin değerlendirilmesi amaçlandı.

Yöntem: Ocak 2016 ile Temmuz 2017 tarihleri arasında, izole BSV yetmezliği nedeniyle n-BSA ile perkütan endovenöz embolizasyon uygulanan kronik venöz bozukluklar için kapsamlı sınıflandırma sistemi (CEAP) evre C1-C4 arası olan, BSV çapı 6-9 mm arasında ve venöz reflü süresi 0,5 sn üzerinde bulunan 72 hasta çalışmaya dahil edildi. Hastalar preoperatif dönemde ve postoperatif 1. ay ve 6. ayda VAS ile değerlendirildi. Tüm hastalara aynı zamanda venöz renkli dupleks ultrasonografi (RDUS) yapıldı. Tüm veriler hasta dosyaları aracılığıyla toplanıp retrospektif olarak değerlendirildi.

Bulgular: Hastaların preoperatif, 1. ay ve 6. ay ortalama VAS skala skorları sırasıyla 6,05, 1,8, 1,66 olarak saptandı. Postoperatif 1. ay ile 6. ay takipleri arasında anlamlı bir farklılık görülmezken ( $p>0,05)$, preoperatif VAS ve postoperatif 1.ay VAS değerleri arasında istatiksel olarak anlamlı fark belirlendi $(p<0,001)$. Ayrıca preoperatif VAS ve postoperatif 6. ay VAS değerleri arasında da istatiksel olarak anlamII fark belirlendi $(p<0,001)$. Hastalara postoperatif 1 . ay ve 6 . ayda yapılan venöz RDUS'da BSV kapanma oranı sırasıyla \%97 ve \%95 idi. izole BSV yetmezliğinde uygulanan n-BSA embolizasyon tedavisinin erken dönem sonuçları hasta memnuniyeti açısından VAS ile değerlendirildiğinde preoperatif dönem ile postoperatif erken dönemde anlamlı derecede olumlu ilişki saptandı.

Sonuç: Izole BSV yetmezliğinin tedavisinde n-butyl siyanoakrilat ablasyon tedavi yönteminin erken dönemde hasta memnuniyetinin değerlendirilmesinde VAS efektif bir değerlendirme metodu olarak kullanılabilir.

Anahtar kelimeler: Venöz yetmezlik, siyanoakrilat, vizüel analog skala

Received: 02.03 .2018

Accepted: 02.08.2018

İstanbul Medeniyet University Faculty of Medicine Department of Cardiovascular Surgery, İstanbul, Turkey

Yazışma adresi: Ebuzer Aydın, İstanbul Medeniyet University Faculty of Medicine Department of Cardiovascular Surgery, İstanbul, Turkey e-mail: ebuzer.aydin@medeniyet.edu.tr

Yazarların ORCiD bilgileri:

M.Ş.B. 0000-0001-9442-889X, C.K. 0000-0002-1348-2411, M.A. 0000-0003-1363-4267, A.Ö. 0000-0001-8284-6656, E.Ş.D.Y. 0000-0003-0629-660X, E.A. 0000-0002-9822-0022 
M.Ş. Bademci ve ark., Evaluation of early patient satisfaction with visual analogue scale in the treatment of isolated great saphenous vein insufficiency with $n$-Butyl cyanoacrylate ablation

\section{Giriş}

Kronik venöz yetmezlik (KVY); toplumda kadınlarda \%1-40, erkeklerde ise \%1-17 oranında görülen ${ }^{1}$, bacakda ağrı ve şişlik yakınmalarından dolayı kişinin yaşam kalitesini bozabilen², eğer tedavisiz bırakılırsa trombozla ve hatta ülserasyonlarla seyredebilen önemli bir hastalıktır³. Büyük safen ven (BSV) yetmezliği tedavisi için günümüzde tedavi kılavuzları incelendiğinde, ilk tedavi yöntemi olarak daha az girişimsel olmasıyla birlikte, yüksek güvenlik ve başarı oranları sayesinde endovenöz termal ablasyon yöntemleri (EVTA), cerrahi yüksek ligasyon ve stripping yöntemlerinin yerini almış bulunmaktadır ${ }^{4}$. Bu yeni teknikler tümesan anestezi kullanımını gerektirir. Ancak tümesan anestezi; daha uzun işlem süresi, postoperatif ağrı, ekimoz, duysal sinir arazı gibi yan etkilere yol açabilmektedir ${ }^{5}$. Tümesan anestezinin bu etkilerini bertaraf edebilmesi amacıyla tıpta doku adezyonu amaçlı kullanılan siyanoakrilat molekülü ${ }^{6}$, uzun yıllardır intrakranial arteriovenöz malformasyonlarda ve peptik varislerin endoskopik intravenöz embolizan tedavisinde de kullanılmaktadır ${ }^{7,8}$.

Girişim uygulanan hastaların işlem sonrası memnuniyetlerinin değerlendirmek, nümerik olarak belirlenemeyen bazı değerleri sayısal biçimde anlamlandırabilmek için vizuel analog skala (VAS) kullanılabilir. VAS; eşit aralıklar halinde bölünmüş $10 \mathrm{~cm}$ 'lik uzunlukta düşey ya da yatay planda "ağrısız" ile "en şiddetli ağıı" algısı arasında hasta bazlı ölçüm sağlayan bir şemadır ${ }^{9}$.

Bu çalışmada, izole BSV yetmezliğinin tedavisinde n-butyl siyanoakrilat ablasyon ( $n-B S A)$ tedavi yönteminin erken dönemde etkinliğinin ve vizüel analog skala kullanılarak hasta memnuniyetinin değerlendirilmesi amaçlanmıştır.

\section{GEREÇ ve YÖNTEM}

Çalışmaya Ocak 2016 ile Temmuz 2017 tarihleri arasında, izole BSV yetmezliği nedeniyle n-BSA ile perkütan endovenöz embolizasyon uygulanan 72 hasta dahil edildi. Çalışmaya dahil edilme kriterleri 19-65 yaş grubunda olup, CEAP sınıflaması evre C1-C4 arası semptomatik olan, BSV çapı dizüstü seviyede 6-9 mm arasında ve reflüsü süresi 0,5 sn üzerinde olan hastalar olarak belirlendi. Geçirilmiş pulmoner emboli, yüzeyel tromboflebit veya derin ven trombozu olan, tortioz BSV olan, gebe olan, immobil veya malignensisi olan, bilinen siyanoakrilat duyarlılığı olan, daha öncesinde GSV girişimi olan, semptomatik periferik arter hastalığı olan (ayak bileği/dirsek indeksi $<0,9$ ) ve ciddi femoral, popliteal veya perforan venlerde ciddi yetmezliği olan, izole BSV yetmezliği yanında varis pakeleri olan hastalar çalışmaya dahil edilmedi. Tüm hastalar işlem öncesi detaylıca bilgilendirildi ve yazılı onamları alındı. Hastalara BSV yetmezliği açısından alt ekstremite venöz renkli dupleks ultrasonografi (RDUS) tetkiki yapıldı. Tüm hastalar işlem günü major bir komplikasyon gelişmeksizin taburcu edildi. Varis çorabı takiplerde kullanılmadı. İşlem sonrasında 1. ay kontrollerine kadar venotonik ilaç verildi. Hastalara preoperatif ve işlem sonrası 1 . ay ve 6 . ay da venöz RDUS tetkiki yaptırıldı ve VAS (Figür 1 ) ile skorları hesaplandı. İşlem öncesi ve sonrasında tüm veriler toplandı. Retrospektif olarak değerlendirildi.

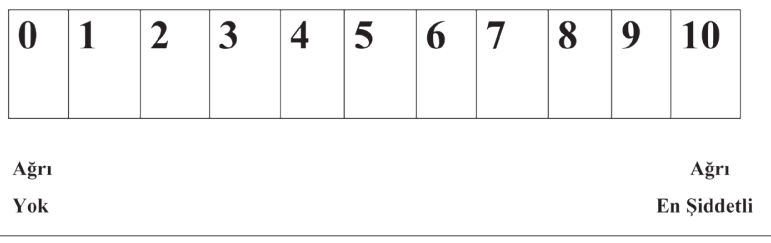

Figür 1. Kullanılan vizüel analog skala.

\section{Siyanoakrilat Ablasyon Tekniği}

Tüm girişimler ameliyat odasında standart steril şartlarda lokal anestezi ile yapıldı. Tüm hastalara VVSS (VariClose Vein Sealing System Biolas, Ankara, Türkiye) herbiri $1 \mathrm{ml}$ polimer kökenli n-BSA teslim kateteriyle kullanıldı. İşlem seti; $6 \mathrm{~F}$ damar içi girişim seti, 0,035 inch kılavuz tel, 3 cc enjektör, enjeksiyon tabancası, enjeksiyon adaptörü, markerlı $5 \mathrm{~F}$ kateter ve $4 \mathrm{~F}$ mikrokateter içermekte idi. Uygun steril örtüm sonrası RDUS kılavuzluğunda safen ven perkutanöz yöntemle dizüstü segmentten kanüle edildi. Damar içi girişim seti safen vene yerleştirilip markerlı kateter 
safenofemoral bileşke $3 \mathrm{~cm}$ gerisine kadar ilerletildi. Teslim kateter sistem hazırlandı ve n-BSA solüsyon injeksiyon tabancasına yerleştirildi. Mikrokateter $5 \mathrm{~F}$ kateter içerisinden ilerletildi, safenofemoral bileşke $3 \mathrm{~cm}$ gerisinde olacak şekilde yerleştirildi. RDUS eşliğinde kateter yeri doğrulandıktan sonra solüsyon verilmeden önce bolus polimerin derin venöz sisteme kaçmasını engellemek için safen ven proksimal segmente venöz doppler usg probu kompresyonuyla mikrokateter sistemi doldurma amaçlı 1 sn süreyle 2 kez tetkileme yapıldı. Devamında tabancanın tetik sistemine 5 sn süreyle basılarak kateter saniyede $2 \mathrm{~cm}$ geri çekildi. Eşzamanlı olarak RDUS probu ile basınç uygulandı. Her 5 sn.'lik tabanca tetiklenmesiyle 0,3 cc polimer yani damara $\mathrm{cm}$ başına $0,03 \mathrm{cc}$ polimer verildi. Tüm safen ven segmentleri embolize edilene kadar işleme devam edildi. Prosedür sonrası işlem uygulanan safen ven segmentleri doppler ile kontrol edildi. Hiçbir hastada prosedür sonunda flebektomi veya skleroterapi gibi bir ek girişim yapılmadı.

\section{İstatistiksel Analiz}

Sayısal veriler ortalama ve standart sapma olarak, kategorik veriler ise sayı ve yüzde olarak gösterildi. Birbiri ile ilişkili iki yada daha fazla değişkene ait dağıIımların karşılaştırılarak dağılımlar arası bir fark olup olmadığını test etmek amacıyla friedman testi kullanıldı. Friedman testi sonrasinda genel anlamlılık elde edilmesi durumunda alt grup analizler wilcoxon testi kullanılarak yapıldı. İstatiksel analiz için SPSS (IBM Software) programı kullanıldı. Tüm analizlerde istatistiksel anlamlılık $p<0,05$ olarak kabul edildi.

\section{BULGULAR}

İzole BSV yetmezliği nedeniyle perkütan n-BSA endovenöz embolizasyon uygulanan 72 hasta çalışmaya dahil edildi. Hastaların ortalama yaşı 41.6 (aralık $19-65$ yaş) yıl idi. Kadın hastalar tüm kohortun \%52 $(n=38)$ 'sini oluşturmaktaydı. CEAP sınıflamasına göre hastalar değerlendirildiğinde, hastaların $\% 2,8^{\prime} i \mathrm{C} 1$ $(n=2), \% 50$ 'si C2 ( $n=36), \% 38$ i C3 ( $n=28)$ ve \%8,3'ü C4 $(n=6)$ idi. Medyan BSV çapı $7 \mathrm{~cm}$ (aralık 6-9 cm) idi. Hastaların ana semptomları incelendiğinde,
$\% 58,3^{\prime}$ ünde ağrı $(n=42), \% 27,7$ 'sinde şişlik $(n=20)$, $\% 8,3$ 'ünde kaşıntı $(n=6), \% 5,5$ 'inde ağırlık hissi $(n=4)$ belirlendi. Hastaların preoperatif ve demografik özellikleri Tablo 1'de gösterildi. Postoperatif derin ven trombozu, pulmoner emboli ve paresteziye rastlanmadı, 2 hastada flebit $(\% 2,7), 1$ hastada cilt pigmentasyonu $(\% 1,3)$ ve 1 hastada $(\% 1,3)$ girişim bölgesinde ekimoz gözlendi. Operasyon sonrası ve erken dönem takiplerde görülen komplikasyonlar Tablo 2'de özetlendi. Hastaların preoperatif, 1 . ay ve 6 . ay ortalama VAS skorları sırasıyla 6,05, 1,8, 1,66 olarak saptandı

Tablo 1. Hastaların preoperatif ve demografik verileri $(n=72)$.

\begin{tabular}{|c|c|}
\hline Cinsiyet (Kadın/Erkek) n (\%) & $38(52) / 34(48)$ \\
\hline Yaş ortalama \pm standard sapma (min:maks) & $41.63 \pm 10.82(19: 65)$ \\
\hline Ana semptom & n (\%) \\
\hline Ağrı & $42(58,3)$ \\
\hline Şişlik & $20(27,7)$ \\
\hline Kaşınt & $6(8,3)$ \\
\hline Ağırlık Hissi & $4(5,5)$ \\
\hline BSV Çap (mm) median (min:maks) & $7(6: 9)$ \\
\hline \multicolumn{2}{|l|}{ CEAP Evre } \\
\hline C1 & $2(2,8 \%)$ \\
\hline $\mathrm{C} 2$ & $36(50 \%)$ \\
\hline C3 & $28(38,8 \%)$ \\
\hline C4 & $6(8,3 \%)$ \\
\hline
\end{tabular}

Tablo 2. Postoperatif Komplikasyonlar.

\begin{tabular}{ll}
\hline & $\mathbf{n}(\%)$ \\
\hline Filebit & $2(2,8)$ \\
Cilt Pigmentasyonu & $1(1,3)$ \\
Ekimoz & $1(1,3)$ \\
\hline
\end{tabular}

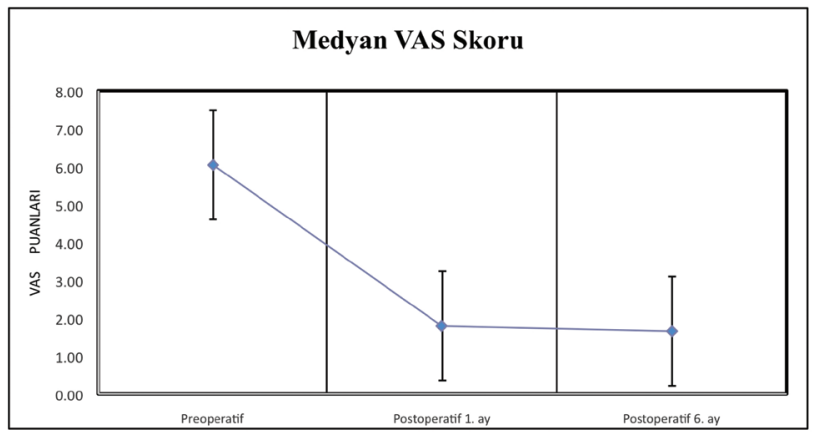

Figür 2. Kullanılan vizüel analog skala. 
(Figür 2). Postoperatif 1. ay ile 6. ay takipleri arasında anlamlı bir farklılık görülmezken ( $p>0,05)$, preoperatif VAS ve postoperatif 1 . ay VAS değerleri arasında istatiksel olarak anlamlı fark tespit edildi $(p<0,001)$. Ayrıca preoperatif VAS ve postoperatif 6 . ay VAS değerleri arasında da istatiksel olarak anlamlı fark tespit edildi $(p<0,001)$ (Tablo 3). Hastalara işlem sonrası 1. ay ve 6. ayda yapılan venöz RDUS'da BSV kapanma oranı sırasıyla \%97 ve \%95 idi (Figür 3). Hiçbir hastada total rekanalizasyon gözlemlenmedi. Sadece 2 hastada 1. ay, 4 hastada da 6 . ay kontrol venöz RDUS'de parsiyel rekanalizasyon izlendi.

Tablo 3. İşlem öncesi ve sonrası VAS skoru analizi.

\begin{tabular}{lll}
\hline Vizüel Analog Skala (VAS) & medyan (min:maks) & $\mathbf{p}$ \\
\hline Pre-op. $\rightarrow$ Post-op 1. ay & $6(4: 8) \rightarrow 2(0: 4)$ & $<0,001^{*}$ \\
Pre-op $\rightarrow$ Post-op 6. ay & $6(4: 8) \rightarrow 2(0: 3)$ & $<0,001^{*}$ \\
Post-op 1. ay $\rightarrow$ Post-op 6. ay & $2(0: 4) \rightarrow 2(0: 3)$ & $>0,05$ \\
\hline
\end{tabular}

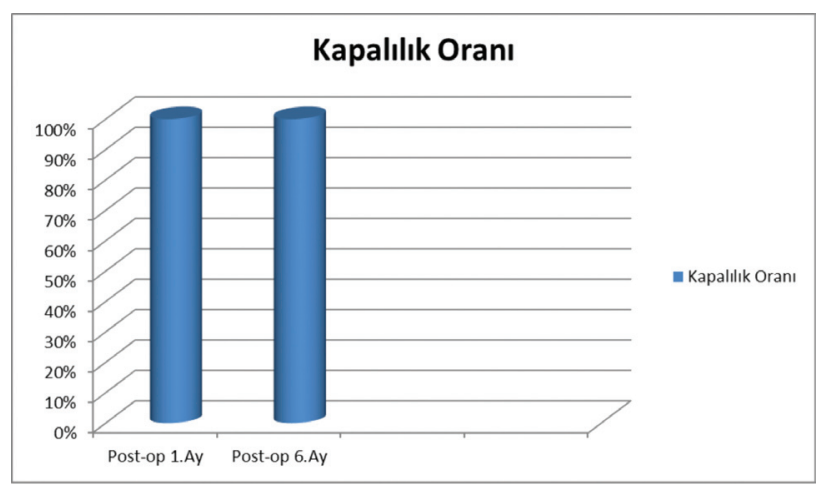

Figür 3. n-BSA embolizasyonsonrası Venöz RDUS'da BSV kapalılık oranları.

\section{TARTIŞMA}

Alt extremite izole BSV yetmezliğinin tedavi metodlarını invaziv cerrahi girişimler (Safen ven stripping, yüksek ligasyon) oluşturmakta iken ${ }^{10}$, son yıllarda EVTA yöntemleri yüksek başarı oranlarıyla altın standart haline gelmiştir ${ }^{4}$. Ancak bu işlemlerin yapılabilmesi için tümesan anestezinin gerekli olması ve bununda postoperatif ağrıya, çoklu ponksiyona bağlı morarmaya ve duysal sinir hasarına neden olabilmesi farklı tedavi yöntemlerinin geliştirilmesine sebep olmuştur ${ }^{11}$.
Bu nedenle ilk defa Almeida ve ark. ${ }^{12}$ tarafından BSV yetmezliğinde n-BSA'ın kullanılmaya başlanmasıyla tümesan anestezi kullanımına gereksinim kalmamıştır. Bu çalışma incelendiğinde, BSV'nin 2 yıllık oklüzyon oranları \%92, Morrison ve ark'nın ${ }^{13} 3$ aylık erken dönem oklüzyon oranları ise \%99 olarak bildirilmiş olup, bizim çalışmamızda da literatürle uyumlu (6 aylık oklüzyon oran \%95) benzer sonuçlar elde edilmiştir.

Endovenöz yolla n-BSA damar endoteline ulaştıktan sonra, ultrason transdüseriyle elle yapılan sıkıştırma ve ardından bekleme aralığı sayesinde siyanoakrilat maddesinin polimerizasyonun 3 evresinden yararlanılır. Illk evrede yaklaşık 10 saniye süren çekme kuvvetlerinde hızlı bir artış, ikinci evrede 1 dk.'ya kadar sabit bir gerilme kuvveti ve üçüncü evredede artan gerilme kuvvetiyle son polimerizasyon elde edilir ${ }^{14}$.

Literatüre bakıldığında n-BSA ile uygulanan embolizasyon tedavisinde her ne kadar düşük yan etki insidansı görülsede olası trombüs tehdidini ortadan kaldırma amacıyla safenofemoral bileşkeye olan mesafenin $5 \mathrm{~cm}$.'de tutulması gerektiğini savunan çalışmalar olsa da ${ }^{14-15}$, yaptığımız çalışma bu mesafe $3 \mathrm{~cm}$ olarak belirlendi ve hiçbir trombüs tehdidiyle karşılaşılmadı. Bu komplikasyonunun gelişmemesi için etkin venöz RDUS kullanımı ve eş zamanlı olarak ablasyon uygulanan damar segmentine tam oklüzyon izlenene kadar kompresyonunun sürdürülmesi gerektiğini düşünmekteyiz.

Kronik venöz yetmezliğinin gerek medikal ve gerekse cerrahi tedavisi sonrasında kompresyon çorabı yaygın olarak kullanılmaktadır. Çalışmamızda, hastalara müdahale sonrasında kompresyon çorabı kullanılmadı. Bu konuda literatür incelendiğinde, alt extremite izole BSV yetmezliğinin n-BSA ile embolizasyonu sonrasında kompresyon çorabı kullanımı hakkında bir görüş birliğine rastlanmamakla birlikte, kompresyon çorabının kullanılmadığı çalışmalar da yer almaktadır ${ }^{16,17}$. Bu konudaki kararın uygulamayı yapan hekimce verilmesinin uygun olduğunu düşünmekteyiz.

BSV yetmezliğinde uygulanan n-BSA embolizasyon tedavisinde erken dönem oklüzyon oranları yüksek 
saptanmış olsa da, elde edilen öznel hasta memnuniyetinin belirlenmesine dair literatürde sınırlı sayıda çalışma mevcuttur. Bu bağlamda bu çalışmada görsel ve tüm hastalara kolay uygulanabilirliği olan VAS kullanılarak hasta memnuniyeti değerlendirilmiştir.

Visual Analog Skala sayısal olarak ölçülemeyen bazı değerleri sayısal hale çevirmek için kullanılır. On cm lik bir çizginin iki ucuna değerlendirilecek parametrenin iki uç tanımı yazılır ve hastadan bu çizgi üzerinde kendi durumunun nereye uygun olduğunu bir çizgi çizerek veya nokta koyarak veya işaret ederek belirtmesi istenir. Yapılan değerlendirmelerde düzenli bir dağılımın oluşması, ölçüm yönteminin kolay anlaşılır ve yinelenebilir olması VAS'ın avantajları arasında gösterilebilirken, ileri yaş grubunda düşen algı ve koordinasyon becerilerinden dolayı uygulama güçlükleri, hastaların işaretlemeleri acelece ve rastgele yapabilecek olması, kontrollerde önceki ağrı skalasının kullanılabilinir olmasından dolayı hastanın etki altında kalabilecek olmasıda dezavantajları olarak sayılabilir ${ }^{9}$.

Kronik venöz yetmezlik gibi hastalıklarda kronik ağrı şiddetinin ölçümünde kullanılan VAS, geçerli ve güvenilir bir ölçüdür ${ }^{18,19}$. Ancak benzer güvenilirliğini Kelly ve ark. ${ }^{20}$ akut ağrı üzerine yaptığı çalışmada sağlayamamaktadır.

İzole BSV yetmezliğinde uygulanan n-BSA embolizasyon tedavisinin erken dönem sonuçları hasta memnuniyeti açısından VAS ile değerlendirildiğinde, preoperatif dönem ile postoperatif erken dönemde anlamlı derecede olumlu ilişki saptanmıştır. n-BSA endovenöz embolizasyonu yüksek başarı oranları, tümesan anestezi gerektirmemesi ve düşük yan etki insidansıyla tercih edilebilir bir yöntemdir. Daha kapsamlı ve uzun dönem içeren çalışmalara gerek olmakla birlikte, uygulanan tekniğin hasta memnuniyetinin değerlendirilmesinde VAS efektif bir değerlendirme metodu olarak kullanılabilir.

Bu çalışmada, yazarlarla ilgili herhangi bir çıkar çatışması bulunmamaktadır.

\section{KAYNAKLAR}

1. Lo YF, Yang $\mathrm{CH}$. Stripping and ligation of the saphenous vein. Semin Cutan Med Surg. 2005 Dec;24(4):200-8.

https://doi.org/10.1016/j.sder.2005.10.004

2. Pannier F, Rabe E. Progression in venous pathology. Phlebology. 2015 Mar;30(1 Suppl):95-7.

https://doi.org/10.1177/0268355514568847

3. Eklof B, Perrin M, Delis KT, Rutherford RB, Gloviczki P. American Venous Forum, European Venous Forum, International Union of Phlebology, American College of Phlebology, International Union of Angiology. Updated terminology of chronic venous disorders: the VEIN-TERM transatlantic interdisciplinary consensus document. J Vasc Surg. 2009;49:498-501. https://doi.org/10.1016/j.jvs.2008.09.014

4. Gloviczki P, Comerato AJ, Dalsing MC, et al. The care of patients with varicose veins and associated chronic venous diseases: clinical practice guidelines of the Society for Vascular Surgery and the American Venous Forum. J Vasc Surg. 2011;53:2S-48S.

https://doi.org/10.1016/j.jvs.2011.01.079

5. Almeida JI, Kaufman J, Göckeritz O, Chopra P, Evans MT, Hoheim DF, Makhoul RG, Richards T, Wenzel C, Raines JK. Radiofrequency endovenous ClosureFAST versus laser ablation for the treatment of great saphenous reflux: a multicenter,singleblinded, randomized study (RECOVERY study). J Vasc Interv Radiol. 2009 Jun;20(6):752-9.

https://doi.org/10.1016/j.jvir.2009.03.008

6. Bruns TB, Worthington JM. Using tissue adhesive for wound repair: a practical guide to Dermabond. Am Fam Physician. 2000 Mar 1;61(5):1383-8.

7. Linfante I, Wakhloo AK. Brain aneurysms and arteriovenous malformations: advancements and emerging treatments in endovascular embolization. Stroke. 2007;38:1411-7. https://doi.org/10.1161/01.STR.0000259824.10732.bb

8. Labenz J, Börsch G. Bleeding gastric and duedonal varicose veins: endoscopic embolisation using tissue adhesives. Dutsch Med Wochenschr. 1992;117:1274-7. https://doi.org/10.1055/s-2008-1062441

9. Gücü $A$, Erdolu B, Ay D, et al. The Evaluation of Patient Satisfaction With Visual Analog Scale After Treatment of Varicosities With Endovenous Laser Ablation: Case Series. Turkish Journal of Vascular Surgery. 2014, vol 23, Issue 1.

10. Teruya TH, Ballard JL. New approches for the treatment of varicose veins. Surg Clin North Am. 2004;84(5):1397-417, viii-ix. https://doi.org/10.1016/j.suc.2004.04.008

11. Bademci MS, Tayfur K, Ocakoglu G, et al. A new percutaneous technique: N-butyl cyanoacrylate adhesive for the treatment of giant saphenous vein insufficiency. Vascular. 2018 Apr;26(2):194-7. https://doi.org/10.1177/1708538117724647

12. Almeida JI JJ, Mackay E, et al. First human use of cyanoacrylate adhesive for treatment of 243 saphenous vein incompetence. J Vasc Surg. 2013;1:174-80.

13. Morrison N, Gibson K, McEnroe S, et al. Randomized trial comparing cyanoacrylate embolization and radiofrequency ablation for incompetent great saphenous veins (VeClose). J Vasc Surg. 2015;61:985-94. https://doi.org/10.1016/j.jvs.2014.11.071

14. Tekin Ai, Tuncer ON, Memetoğlu ME, et al. Nonthermal, Nontumescent Endovenous Treatment of Varicose Veins. Ann Vasc Surg. 2016 Oct;36:231-5. https://doi.org/10.1016/j.avsg.2016.03.005 
M.Ş. Bademci ve ark., Evaluation of early patient satisfaction with visual analogue scale in the treatment of isolated great saphenous vein insufficiency with $n$-Butyl cyanoacrylate ablation

15. Proebstle TM AJ, Dimitri S, et al. The European multicenter cohort study on cyanoacrylate embolization of refluxing great saphenous veins. J Vasc Surg: Venous Lymphat Disord 2015;3:2-7.

https://doi.org/10.1016/j.jvsv.2014.09.001

16. Arslan M, Albaş $S$, Küçükerdem HS, Pamuk G, Can H. Vizüel Analog Skala ile Kanser Hastalarında Palyatif Ağrı Tedavisinin Etkinliğinin Değerlendirilmesi. Fam Pract Palliat Care. 2016 Apr;1(1):5-8. https://doi.org/10.22391/920.182939

17. Ünay K, Bilge A, Ünay F, Akan K, Poyanlı O. A similar analgesic protocol may be use after total hip and knee arthroplasty. Göztepe Tıp Dergisi. 2014;29(1):32-37.

18. Kelly A M. Does the clinically significant difference in visual analog scale pain scores vary with gender, age, or cause of pain? Acad Emerg Med. 1998;5(11):1086-90.

https://doi.org/10.1111/j.1553-2712.1998.tb02667.x 